Journal of Biotechnology and Strategic Health Research

\author{
Derleme / Review
}

http://dergipark.org.tr/tr/pub/bshr

\title{
COVID-19 (Yeni Tip Koronavirüs) Günlerinde Dahi Anne Sütü Yine Çok Önemli!
}

\author{
Even in COVID-19 (Novel Coronavirus) Days, Breast Milk is Still Very Important too!
}

(D) $₫$ Mustafa Törehan Aslan", (D) İlke Özer Aslan², (D) Öner Özdemir³

\begin{abstract}
${ }^{1}$ İstanbul Üniversitesi İstanbul Tip Fakültesi, Çocuk Sağlığı ve Hast. Anabilim Dalı, Neonatoloji Bilim Dalı, İstanbul
${ }^{2}$ Sağlık Bilimleri Üniversitesi, Bakırköy Dr. Sadi Konuk Eğitim ve Araştırma Hastanesi, Kadın Hast. ve Doğum Anabilim Dalı, İstanbul

${ }^{3}$ Sakarya Üniversitesi Tip Fakültesi, Sakarya Üniversitesi Eğitim ve Araştırma Hastanesi, Çocuk Sağlığı ve Hast. Anabilim Dalı,

Çocuk İmmünolojisi ve Alerji Hastalıkları Bilim Dalı, Sakarya

ORCID ID: Mustafa Törehan Aslan 0000-0002-3966-4635, İlke Özer Aslan 0000-0002-3175-8354, Öner Özdemir 0000-0002-5338-9561

*Sorumlu Yazar / Corresponding Author: Uzm. Dr. Mustafa Törehan Aslan, e-posta / e-mail: torehanaslan@yahoo.com

Geliş Tarihi / Received : 16-04-2020 Kabul Tarihi / Accepted: 19-04-2020 Yayın Tarihi / Online Published: 30-04-2020

Atıf Gösterimi/How to Cite: Aslan M.T., Özer Aslan İ., Özdemir Ö. COVID-19 (Yeni Tip Koronavirüs) Günlerinde Dahi Anne Sütü Yine Çok Önemli!. J Biotechnol and Strategic Health Res. 2020;1(Özel Sayı):111-115
\end{abstract}

Öz

Yeni tip koronavirüs (2019-nCoV / SARS-CoV-2) enfeksiyonu sonucu oluşan COVID-19 hastalığ1, ek hastalığı olmayan çocuk ve gençlerin aksine yaşlılarda ve ek hastalığı olan kişilerde daha ağır seyirli ve semptomatik yaşanmaktadır. Ancak fetusa geçiş yolları, yenidoğanlarda ve bebeklerde virüsün klinik seyri, laboratuvar değişiklikleri ve prognozu hakkında kanıt düzeyi yüksek yeterli bilgiler henüz yoktur. Salgınlar gibi olağanüstü koşullarda sağlığın korunmasında anne sütü ile beslenmenin önemi büyüktür. Özellikle enfeksiyonlardan korunmada anne sütünün antimikrobiyal, antienflamatuar ve immünomodülatör olumlu yönleri önem arz etmektedir. Anne sütü içeriğinde bulunan özellikle laktoferrin, lizozim, salgısal IgA, vb. diğer ajanlar ile doğal immünite oluşmaktadır. Şu anki bilimsel veriler çerçevesinde annede SARS-CoV-2 kanıtlanmış ve şüpheli enfeksiyon varlığında anne sütünün verilmesinde kesin bir engel görünmemektedir. Tüm Dünya’da yaşanan COVID-19 salgını sürecinde bebek sağlığı açısından birçok yararlı ve olumlu etkileri olan anne sütü ile beslenmeye gerekli hijyen ve izolasyon kurallarına uyularak, aydınlatılmış onam ile birlikte ailenin de görüşünün sürece dahil edilerek devam edilmesi önem arz etmektedir.

Anahtar COVID-19, anne sütü, emzirme, yenidoğan

Kelimeler

Abstract

COVID-19 disease caused by a novel type coronavirus (2019-nCoV / SARS-CoV-2) infection is more severe and symptomatic in older people and people with an additional disease, unlike children and young people without additional disease. However, there is not yet sufficient evidence about the transition routes to the fetus, the clinical course of the virus, laboratory changes and prognosis in newborns and infants. Breastfeeding is of great importance in maintaining health in extraordinary conditions such as outbreaks. Especially, positive antimicrobial, anti-inflammatory and immunomodulatory aspects of breast milk are important in preventing infections. Natural immunity is formed with other agents, especially lactoferrin, lysozyme, secretive IgA, etc., contained in breast milk. Based on current scientific data, there is no clear obstacle in the delivery of breast milk in the presence of suspected or proven SARS-CoV-2 infection in the mother. During the COVID-19 pandemic throughout the world, it is important to continue breastfeeding, which has many beneficial and positive effects in terms of baby health, by following the necessary hygiene and isolation rules, along with obtaining the written informed consent from parents including the family's opinion.

Keywords COVID-19, breast milk, breastfeeding, newborn 


\section{GIIRIŞ}

COVID-19 hastalığı (yeni tip koronavirüs enfeksiyonu) ek hastalığı olmayan çocuk ve genç bireylerden ziyade yaşl1larda ve ek hastalığı olan bireylerde daha semptomatik ve ağır seyirli görülmektedir. Ancak fetusa geçiş yolları, yenidoğanlarda ve bebeklerde virüsün klinik seyri, laboratuvar değişiklikleri ve prognozu hakkında kanıt düzeyi yüksek yeterli bilgiler henüz yoktur. Dünya Sağlık Örgütü (WHO) toplumun sağlığı için bebeklerin doğumdan sonraki ilk 6 ay tek başına anne sütü ile beslenmelerini ve sonrasında ek gıdalara başlanarak emzirmenin en az 2 yaşına kadar da sürdürülmesini önermekte ve salgınlar gibi olağanüstü durumlarda dahi anne sütü ile beslenmenin sürdürülmesi gerektiğini belirtmektedir. ${ }^{1,2}$

\section{Anne Sütünün Faydaları}

Anne sütünün birçok faydasının olduğu bilinmekle birlikte, en önemli özellikleri arasında antimikrobiyal, antienflamatuar ve immünomodülatör etkileri yer almaktadır. Laktoferrin, lizozim, fibronektin, salgısal IgA, musin, C3, oligosakkaritler, lipitler başlıca antimikrobiyal faktörlerdendir. Vitamin A, C, E, katalaz, glutatyon peroksidaz, alfa-1 antitripsin, alfa-1 antikimotripsin, prostaglandin E1-2, EGF, TGF antienflamatuar faktörlerdir. Ayrıca anne sütünde interlökinler, interferon gama ve TNF- $\alpha$ gibi immünomodülatörler de bulunmaktadır. Monosit, makrofaj, PMNL, T ve B lenfositler ise hücresel bileşenlenleri oluşturmaktadır. Başta salgısal IgA olmak üzere diğer inmünoglobulinler de salmonella, şigella, kolera, poliovirüs, rotavirüs, RSV ve diğer mikroorganizmalarla gelişen enfeksiyonları önler. Anne sütü bu özellikleri ile bebeği sepsis, bakteriyemi, menenjit, solunum yolları enfeksiyonları, gastroenteritler, üriner sistem enfeksiyonları ve akut otitis mediadan korur. ${ }^{3}$

COVID-19 hastalığı şüpheli veya kanıtlanmış anne bebekleri dahil olmak üzere özellikle ilk 6 ay içindeki bebekler için en iyi beslenme kaynağı anne sütüdür. COVID-19 hastalığg kanıtlanmış anne, belirtilen uygun önlemleri aldığı sürece bebeğini emzirebilir. Anne sütü çoğu hastalık- lara karşı koruyucu olduğu gibi solunum yolu hastalıklarına karşı da korumaya yardımcı ve faydalı olabilecek birçok antikor ve immünolojik ajanlar içerir. Her geçen gün ortaya çıkan kanıtlar bir çocuğun büyümesi, gelişimi ve sağlığ için emzirmenin önemini desteklemektedir. ${ }^{4}$

Literatürden COVID-19 hastalığg Olan Anne Örnekleri COVID-19 hastalığı kanıtlanmış orta yaşlardaki üç gebenin değerlendirildiği çalışmada, ilk gebenin hastaneye ateş şikayeti ile başvurduğu ve toraks görüntülemesinde akciğerlerinde yaygın infiltrasyon olduğu görülmüş, orofarengeal ve rektal sürüntü örneklerinde SARS-CoV-2 pozitif saptanmışken, anne sütü, vajinal sürüntü ve plasenta örnekleri negatif olarak sonuçlanmıştır. Bebeğinden alınan örneklerde ise virüs tespit edilmemiştir. İkinci gebe de 37. gestasyonel haftada ateş şikayeti ile hastaneye başvurmuş ve toraks görüntülemesinde yaygın akciğer infiltrasyonları mevcut olup ve boğaz sürüntüsü örneğinde SARS-CoV-2 pozitif saptanmıştır. Otuz sekizinci gestasyonel haftada da sezaryen ile doğumu gerçekleştirilmiş ve bebekten gönderilen örneklerde ise SARS-CoV-2 negatif olarak sonuçlanmış olup bebekte herhangi bir klinik bulgunun görülmediği bildirilmiştir. Yine ateş ve akciğer semptomları ile başvuran üçüncü gebenin alınan örneklerinde SARSCoV-2 pozitif saptanmış, bebeğinde de herhangi bir bulgu veya alınan örneklerinde SARS-CoV-2'ye rastlanılmamıştır. ${ }^{5}$ COVID-19 hastalığg şüpheli veya kanıtlanmış annelerde laktasyonun devamı için süt sağılmaya devam edilebilir. Eğer mümkünse SARS-CoV-2 açısından anne sütü analizi yapılabilir. Uygun hijyen, maske takılması ve izolasyon koşullarına azami şekilde uyularak annenin ve bebeğin de klinik durumu uygunsa annenin bebeğini emzirmesine veya sağılmış sütünün bebeğe verilmesine aile ile de görüşülerek karar verilmelidir. ${ }^{6}$ Emziren annenin COVID-19 hastalığı tanısı alan kişi ile temas öyküsü varlığında da emzirmeye ara verilmemelidir. Böyle bir durumda gerekli önlemler alınarak emzirmeye devam edilmelidir. 


\section{COVID-19 hastalığı Şüpheli veya Kanıtlanmış}

\section{Annenin Yapması Gerekenler}

COVID-19 hastalığı şüpheli veya kanıtlanmış annenin emzirirken ya da sütünü sağarken alması gereken önlemler, maske takması, emzirmeden önce ellerini en az 20-30 saniye süre ile etkin olarak yıkaması (ellerin iç yüzleri, dış yüzleri, parmak araları, başparmak arası ve ayası, avuç ortası, parmak uçları ve bileklere kadar yıkanması), iyice durulayıp tek kullanımlık havlu ile kurulaması, temizliğin etkin olması için de yüzük ve bilezik gibi ek aksesuarların kullanılmaması, bulunulan ortamın sık havalandırılması, kıyafetlerin $60-90^{\circ} \mathrm{C}$ 'de normal deterjan ile yıkanması, bol sıvı tüketilmesi, dengeli beslenilmesi ve düzenli uykuya dikkat edilmesi olarak özetlenebilir.?

Dünyada ve ülkemizde sıkça sorulan 5 soru ve cevaplarına bakacak olursak: $:^{8-13}$

\section{COVID-19 hastalığı tanısı konulan anne bebeğini} emzirebilir mi?

UNICEF, Academy of Breastfeeding Medicine, WHO ve CDC emzirmenin yararlarını ve anne sütünden diğer solunum yolu virüslerinin bulaşma riskinin önemsenmeyecek kadar az olmasından dolayı, annenin gerekli tüm önlemleri uyguladıktan sonra emzirmeye devam edebileceğini belirtmektedir. SARS-CoV-2 ve diğer koronavirüs enfeksiyonları olan emziren kadınlar üzerinde yapılan sınırlı çalışmalarda anne sütünde şimdiye kadar virüs tespit edilememiştir ancak SARS-CoV-2 enfeksiyonu kanıtlanmış annelerin virüsü anne sütü ile bulaştırıp bulaştıramayacakları henüz bilinmemektedir. Şu anda birincil endişe virüsün anne sütü ile bulaşıp bulaşmayacağından ziyade, enfekte bir annenin emzirme döneminde virüsü solunum damlacıkları ile bulaştırıp bulaştıramayacağıdır. Virüsün bebeğe bulaşmasını engellemeye yönelik önlemler arasında, bebeğin tutulmadan önce ellerin uygun şekilde yıkanması ve bebek ile yakın temas halindeyken "örneğin doğrudan emzirme sırasında” yüz maskesinin takılması yer alır.

\section{COVID-19 hastalığı kanıtlanmış anneler bebeklerin-} den ayrılmalı mı? Bebeklerini doğrudan emzirmek yerine sadece anne sütünün verilmesi mi sağlanmalı?

Emzirme seçimi annelere ve ailelere aittir. Bununla birlikte, Johns Hopkins Medicine tarafından da belirtildiği gibi, SARS-CoV-2 enfeksiyonu olan bir annenin bebeğinden ayrılması kararı bir sağlık ekibi tarafından verilmelidir çünkü, bu süreç anne ve bebeğin sağlı̆̆ını içeren birçok faktöre dayanmaktadır. UNICEF, Academy of Breastfeeding Medicine, WHO ve CDC tarafından belirtildiği üzere, anne ve bebek birlikte kalabiliyorsa, memede emzirme teşvik edilir. Şu anda birincil endişe, virüsün anne sütü ile bulaşıp bulaşmayacağından ziyade, enfekte bir annenin virüsü solunum damlacıklarıyla bebeğe iletip iletmeyeceğidir. Bu nedenle CDC anneye, emzirirken veya sağılmış anne sütünü verirken bir maske takmasını ve emzirmeden önce ve sonra iyi el hijyeni uygulamasını önermektedir.

\section{Emzirme süreci, COVID-19 hastalık riski göz önün-} de bulundurulduğunda güvenli midir? Formül mamaya geçilmeli mi?

UNICEF, emzirmenin acil durumlarda bebek için en güvenilir yöntem olduğunu belirtmektedir. Harvard Tip Fakültesi'nin "Tipta Trendler" adlı makalesinde, COVID-19 hastalığının formül mama üreticisi fabrikalar ve dağıtım depoları yoluyla yayılma riski göz önüne alındığında, bu fabrikaların ve depoların kapatılması gerekiyorsa tedarik zinciri kesintisinin de söz konusu olabileceğine değinmektedir. UNICEF, Academy of Breastfeeding Medicine, WHO ve CDC emzirmenin yararlarını ve anne sütüne diğer solunum yolu virüslerinin bulaşma riskinin önemsenmeyecek kadar az olmasından dolayı, annenin gerekli tüm önlemleri uyguladıktan sonra emzirmeye devam edebileceğini belirtmektedir.

\section{COVID-19 hastalığı kanıtlanmış ve herhangi bir ne-} denden dolayı bir süre bebeğinden ayrılan anne emzirmeye yeniden başlayabilir mi?

Bir süre bebekten ayrılmış ve emzirmeye ara verilmişse, bebek ile tekrar birlikte olunduğunda emzirmeyi tekrar 
başlatabilmek genellikle mümkündür ve tam emzirmeye geri dönüş her zaman mümkün olmasa da mutlaka denenmelidir. Buna yeniden laktasyon denir. Yeniden laktasyon sürecinde WHO ve UNICEF-UK, emzirmenin yönetimi için aşağıdaki temel adımları önermektedir.

- Bol miktarda ten-tene temas, göğüste yalanma ve gögüs masajı dahil olmak üzere hormonal yanıtı artırmak için eylemlere başlanılmalıdır.

- Gögüs masajı ve elle pompa yapmak (8-10 kez/gün), anne bebekten ayrıldığında veya beslemeler arasında anneye yardımcı olabilir.

- Bebek her iki göğüsten 24 saat içinde en az 8-12 kez, her memede en az 15 dakika olmak üzere sık sık emmelidir. Gece beslemelerinin atlanmaması bu süreçte çok önemlidir.

- Göğüs elle pompalanırken bebeğin memede bulundurulması denenmelidir.

- Bebeğin etkili emmesi ve meme ucu travmasını önlemek için bebeğin ağzının memeye iyi oturması sağlanmalıdır.

- Bebeğin dışkı ve idrar çıkışını yakından izlemek gereklidir.

- $\quad$ Anne sütü üretiminin yeniden başlatılabilmesi ve bebeğin büyümesinin kontrolü için ek rehberlik ve destek alınmasının sağlanmasına yardımcı olunmalıdır.

\section{Bebeğimi COVID-19 hastalığına karşı nasıl koruya- bilirim?}

Anne sütü çoğu bebek için en iyi beslenme kaynağıdır ve birçok hastalığa karşı koruma sağlar. Ancak CDC’nin belirttiği üzere, yeni tip bu virüs hakkında kanıta dayalı çok fazla şey bilinmemektedir. Ellerin genellikle en az 20-30 saniye süreyle sabun ve su ile yıkanması, eğer imkan yoksa da alkol bazlı el dezenfektanı kullanarak temizlenmesi önem arz etmektedir. Hasta olan insanlardan kaçınılmalı (öksürme ve hapşırma), sosyal izolasyona azami ölçüde uyulmalıdır. Evin ortak kullanım alanları (masa, sandalye, kapı kolları, uzaktan kumanda, tuvalet, vb.) gün içinde temizlenmeli ve dezenfekte edilmelidir. Yakın temasta maske takılmalıdır. Mümkünse çamaşırlar $60-90^{\circ} \mathrm{C}$ 'de y1kanmalıdır.

\section{SONUÇ}

Şu anki bilimsel veriler çerçevesinde annede kanıtlanımış ve şüpheli COVID-19 hastalığı varlığında anne sütünün verilmesinde kesin bir engel görünmemektedir. Tüm Dünyada yaşanan COVID-19 salgını sürecinde bebek sağlığg açısından birçok yararlı ve olumlu etkileri olan anne sütü ile beslenmeye, gerekli hijyen, maske kullanımı ve izolasyon kurallarına uyularak, aydınlatılmış onam ile birlikte aile görüşünün de sürece dahil edilerek devam edilmesi önem arz etmektedir. 
J Biotechnol and Strategic Health Res. 2020;1(Özel Sayı):111-115

ASLAN, ASLAN, ÖZDEMİR, COVID-19 Anne sütü

\section{Kaynaklar}

1. Guiding principles for feding infants and young children during emergencies. World Health Organization. Geneva, 2004

2. Özdemir Ö. Coronavirus Disease 2019 (COVID-19): Diagnosis and Management (narrative review). Erciyes Med J 2020; 42(3): 00-00. doi:10.14744/ etd.2020.99836.

3. Gür E. Anne sütü ile beslenme. Türk Pediatri Arșivi 2007; 42(ES): 11-15.

4. http://www.euro.who.int/_data/assets/pdf_file/0010/437788/breastfeeding-COVID-19. pdf?ua $=1$ adresinden 14 Nisan 2020'de erişildi.

5. Liu W, Wang Q, Zhang Q, et al. Coronavirus disease 2019 (COVID-19) during pregnancy: A case series. Preprints 2020, 2020020373.

6. COVID-19(SARS-CoV2) enfeksiyonu olan veya şüphesi olan yenidoğan bebeklere neonatal ve perinatal dönemde yaklaşım önerileri rehberi (v.2, 23.03.2020). Türk Neonatoloji Derneği, 2020.

7. Gokcay G, Keskindermirci G. Breastmilk and Covid-19. J Ist Faculty Med. Published online March 23, 2020. doi:10.26650/IUITFD.2020.0025.
8. https://www.bfmed.org/abm-statement-coronavirus adresinden 14 Nisan 2020 'de erişildi.

9. https://www.unicef.org/stories/novel-coronavirus-outbreak-what-parents-should-know adresinden 14 Nisan 2020'de erișildi.

10. https://www.who.int/news-room/q-a-detail/q-a-on-covid-19-pregnancy-childbirth-andbreastfeeding adresinden 14 Nisan 2020'de erișildi.

11. https://www.cdc.gov/coronavirus/2019-ncov/need-extra-precautions/pregnancy-breastfeeding.html?CDC_AA_refVal=https\%3A\%2F\%2Fwww.cdc.gov\%2Fcoronavirus\%2F2019-n cov\%2Fprepare\%2Fpregnancy-breastfeeding.html adresinden 14 Nisan 2020'de erișildi.

12. https://www.cdc.gov/coronavirus/2019-ncov/if-you-are-sick/index.html?CDC_AA_refVal $=$ https\%3A\%2F\%2Fwww.cdc.gov\%2Fcoronavirus\%2F2019-ncov\%2Fhcp\%2Fguidance-prevent-spread.html adresinden 14 Nisan 2020'de erişildi.

13. Özdemir Ö, Pala A. Çocuklarda COVID-19 Enfeksiyonunun Tanıst, Tedavisi ve Korunma Yollari. Journal of Biotechnology and Strategic Health Research. 2020; 4: 14-21. doi:10.34084/bshr.711208 